\title{
DE-FG02-08ER55000
}

\section{Wavebreaking and Particle Trapping in Collisionless Plasmas: Final Report}

\author{
B. A. Shadwick - University of Nebraska-Lincoln
}

\section{Summary}

Our theoretical/computational group is based in the Department of Physics and Astronomy of the University of Nebraska-Lincoln. During the period covered by this grant, our work was focused on the following areas:

1. the fundamental plasma physics of intense laser-plasma interactions, including the nonlinear excitation of plasma wakes for accelerator applications (specifically, the electron density "bubbles" driven by a constantly evolving ultra-relativistic laser pulse);

2. computationally-efficient models of electron beam transport in laser plasma accelerators, including a moment-based approach recently developed by us;

3. laser energy deposition in under-dense plasma and the connection between red-shifting and pumpdepletion;

4. variational formulation of high-fidelity macroparticle models for kinetic plasma simulations;

5. the nonlinear dynamics of wave-particle interaction in plasmas, including our discovery of the phenomenon of electron trapping into an evolving electron density bubbles;

6. new approaches to the numerical modeling of self-injection process, aimed at the reduction of both numerical noise and computational cost (enhancing particle statistics in the collection volume, blob particles etc.);

7. the relativistic nonlinear optics of plasmas, elucidating the intrinsic relation between nonlinear optical evolution of the driver and the dynamics of electron self-injection, including development of the new approaches to dynamic manipulation of the laser pulses to preserve electron beam quality;

8. discovering the critical role of transient nonlinear pulse dynamics for generation of backgroundfree, $\mathrm{GeV}$-class electron beams from finite-length plasmas in the laboratory experiments (by the team DIOCLES); and

9. nonlinear optics of multi-color laser pulse interaction with the plasma, including our recent discovery of the phenomenon of generation of relativistic pulse trains via electromagnetic cascading and manipulation of these trains using three-dimensional, non-resonantly driven plasma waves.

\section{How this grant enhanced my career}

- Funding under this grant was essential in establishing a new plasma theory program at UNL and growing the group to "critical mass." There are now a total of five graduate student (not all funded by this project) and three undergraduates have gone on to study plasma physics in graduate school. 
- Work funded by this grant has lead to 4 invited talks at international conferences. This visibility helped to establish a positive reputation for our new group.

- Work funded by this grant lead to the award of two additional grants in the field of plasma physics (2011-14: NSF grant PHY-1104683 "Multi-Physics Modeling of Intense, Short-Pulse Laser-Plasma Interactions"; 2012-15: DOE-OFES grant DE-SC0008382 "Theory and Modeling of Petawatt Laser Pulse Propagation in Low Density Plasmas")

Besides the PI, the group included (at various stages of this project) one senior research associate (S. Y. Kalmykov), two postdoctoral research associates (E. G. Evstatiev and M. Carrié), graduate students (J. Paxon Reyes, M. M. Tassi, and A. Bouzid), and undergraduate students (F. M. Lee, A. Bouzid, L. Faeh, and K. Bunkers). In the course of the project, we have established and maintained (at no cost to the project) a close research collaboration with the team from CEA, DAM, DIF (Arpajon, France) to carry out simulation studies of injection mechanisms in the blowout regime. We have also closely interacted with the DIOCLES laser team (team leader D. P. Umstadter), supporting their experimental program with theory and simulation, providing the theoretical interpretation of the observed dynamical scenarios of electron injection and acceleration.

While pursuing basic research, we paid special attention to possible applications, such as plasma-based accelerators and rapid, low-noise numerical codes for modeling the laser-plasma interactions. The most important advances have been made in the following areas:

- A dynamic theory of electron trapping into evolving plasma bubbles, including complete characterization of the trapping process at the phase-space level through a non-stationary Hamiltonian theory, accurate evaluation of the collection volume, and derivation of phenomenological trapping conditions in the blowout regime.

- A variational formulation of macro-particle models which eliminate grid-heating and admit arbitrary particle shapes at any desired spatial and temporal accuracy.

- All-optical methods of preserving electron beam quality by eliminating the adverse nonlinear optical processes (such as the pulse phase self-modulation with concomitant deformation into the optical shock) - manipulating the laser pulse using frequency chirp and tailoring plasma density to achieve the favorable evolution scenarios.

- The manipulation of the relativistic pulse trains using the nonlinear refraction of plasmas, and controlling the multi-color pulse focusing and transport in plasmas using the three-dimensional, non-resonantly driven plasma waves.

- The development of computationally efficient, low-noise algorithms of laser and electron beam transport in plasmas, including new approaches to the noise reduction in particle-in-cell codes as enhanced macroparticle statistics in the collection volume.

Members of our group have attended APS Division of Plasma Physics meetings (in 2008-2012) and Advanced Accelerator Concepts Workshops (in 2008, 2010, and 2012) and made a number of contributed and invited presentations. Four invited talks were given by the group members: three at annual APS/DPP meetings (Shadwick in 2008 \& 2013, Kalmykov in 2010) and one at the Sherwood Theory Conference (Shadwick 2013). Theory and simulations provided by our group members contributed to the invited talks given by the members of the DIOCLES laser team (S. Banerjee in 2011 at the annual APS/DPP meeting and CLEO/IQEC-Pacific Rim). We have published the results of our work supported 
by this grant in the leading international journals, including Physics of Plasmas, New Journal of Physics, and Journal of Computational Physics. We have also published a review of our work on theory of electron self-injection as a chapter of book "Femtosecond-Scale Optics," InTech (ISBN: 978-953-307-769-7).

\section{Publications related to work support by this grant}

\section{Peer-reviewed publications:}

1. B. A. Shadwick, C. B. Schroeder, and E. Esarey, Nonlinear laser energy depletion in laser-plasma accelerators, Phys. Plasmas 16, 056704 (2009); http://dx.doi.org/10.1063/1.3124185.

2. S. Y. Kalmykov, A. Beck, S. A. Yi, V. N. Khudik, M. C. Downer, E. Lefebvre, B. A. Shadwick, and D. P. Umstadter, Electron self-injection into an evolving plasma bubble: quasi-monoenergetic laser-plasma acceleration in the blowout regime, Phys. Plasmas 18(5), 056704 (2011); http://dx.doi.org/10.1063/1.3566062.

3. S. Y. Kalmykov, B. A. Shadwick, A. Beck, X. Davoine, and E. Lefebvre, Laser plasma acceleration with negatively chirped pulse: all-optical control over dark current in blowout regime, New J. Phys. 14, 033025 (2012); http://dx.doi.org/10.1088/1367-2630/14/3/033025.

4. B. M. Cowan, S. Y. Kalmykov, A. Beck, X. Davoine, K. Bunkers, A. F. Lifschitz, E. Lefebvre, D. L. Bruhwiler, B. A. Shadwick, and D. P. Umstadter, Computationally efficient methods for modeling laser wakefield acceleration in the blowout regime, J. Plasma Phys. 78(4), 469-482 (2012); http://dx.doi.org/10.1017/S0022377812000517.

5. S. Banerjee, N. D. Powers, V. Ramanathan, I. Ghebregziabher, K. J. Brown, C. M. Maharjan, S. Chen, A. Beck, E. Lefebvre, S. Y. Kalmykov, B. A. Shadwick, and D. P. Umstadter, Generation of tunable, 100-800 MeV quasi-monoenergetic electron beams from a laser-wakefeld accelerator in the blowout regime, Phys. Plasmas 19(5), 056703 (2012); http://dx.doi.org/10.1063/1.4718711.

6. B. A. Shadwick, G. M. Tarkenton, E. Esarey, and Frank M. Lee, Hamiltonian reductions for modeling relativistic laser-plasma interactions, Comm. Nonlinear Sci. Numer. Simul. 17(5), 21532160 (2012); http://dx.doi.org/10.1016/j.cnsns.2011.05.045.

7. S. Banerjee, S. Y. Kalmykov, N. D. Powers, G. Golovin, V. Ramanathan, N. J. Cunningham, K. J. Brown, S. Chen, I. Ghebregziabher, B. A. Shadwick, D. P. Umstadter, B. M. Cowan and D. L. Bruhwiler, A. Beck, and D. P. Umstadter, Stable, tunable, quasi-monoenergetic electron beams produced in a laser wakefield near the threshold for self-injection, Phys. Rev. ST Accel. Beams 16, 031302 (2013); http://dx.doi.org/10.1103/PhysRevSTAB.16.031302.

8. E. G. Evstatiev and B. A. Shadwick, Variational Formulation of Particle Algorithms for Kinetic Plasma Simulations, J. Comput. Phys. 245, 376 (2013);

http://dx.doi.org/10.1016/j.jcp.2013.03.006.

\section{Book chapters:}

1. Serguei Y. Kalmykov, Bradley A. Shadwick, Arnaud Beck, and Erik Lefebvre (2011). Physics of quasi-monoenergetic laser-plasma acceleration of electrons in the blowout regime, FemtosecondScale Optics, Anatoli V. Andreev (Ed.), ISBN: 978-953-307-769-7, InTech, DOI: 10.5772/25062; 
pp. 113-138. Available from:

http://www.intechopen.com/articles/show/title/physics-of-quasi-monoenergetic-laser-plasmaacceleration-of-electrons-in-the-blowout-regime.

\section{Conference proceedings:}

1. B. A. Shadwick and C. B. Schroeder, Physical fidelity in particle-in-cell modeling of small Debyelength plasmas, in The $13^{\text {th }}$ Advanced Accelerator Concepts Workshop, Carl B. Schroeder, Wim Leemans, and Eric Esarey, Editors, AIP Conf. Proc. 1086, 321-327 (2009); http://dx.doi.org/10.1063/1.3080926.

2. S. Y. Kalmykov, A. Beck, S. A. Yi, V. Khudik, B. A. Shadwick, E. Lefebvre, and M. C. Downer, Electron self-injection into an evolving plasma bubble: The way to a dark current free GeV-scale laser accelerator, in The $14^{\text {th }}$ Advanced Accelerator Concepts Workshop, Steven H. Gold and Gregory S. Nusinovich, Editors, AIP Conf. Proc. 1299, 174-179 (2010); http://dx.doi.org/10.1063/1.3520309.

3. B. A. Shadwick, F. Lee, M. M. Tassi, and G. M. Tarkenton, Self-consistent Hamiltonian model of beam transport in a laser-driven plasma accelerator, in The $14^{\text {th }}$ Advanced Accelerator Concepts Workshop, Steven H. Gold and Gregory S. Nusinovich, Editors, AIP Conf. Proc. 1299, 221-226 (2010); http://dx.doi.org/10.1063/1.3520318.

4. J. Paxon Reyes and B. A. Shadwick, Numerical methods for the wave equation, in The $14^{\text {th }}$ Advanced Accelerator Concepts Workshop, Steven H. Gold and Gregory S. Nusinovich, Editors, AIP Conf. Proc. 1299, 256-261 (2010); http://dx.doi.org/10.1063/1.3520324.

5. S. Y. Kalmykov, B. A. Shadwick, and M. C. Downer, All-optical control of nonlinear self-focusing in plasmas using non-resonantly driven plasma wave, in The $14^{\text {th }}$ Advanced Accelerator Concepts Workshop, Steven H. Gold and Gregory S. Nusinovich, Editors, AIP Conf. Proc. 1299, 752-757 (2010); http://dx.doi.org/10.1063/1.3520425.

6. S. Banerjee, S. Kalmykov, N. Powers, V. Ramanathan, N. C.-Smith, K. Brown, S. Chen, A. Moorthi, I. Ghebregziabher, C. Maharjan, B. Shadwick, D. Umstadter, A. Beck, E. Lefebvre, A. Cowan, and D. Bruhwiler, Background-free, quasi-monoenergetic electron beams from a self-injected laser wakefield accelerator, in Proceedings of the International Quantum Electronics Conference and Conference on Lasers and Electro-Optics Pacific Rim 2011 (Optical Society of America, 2011), paper C1094; pp. 872-874; ISBN 978-0-9775657-7-1; DOI: 10.1109/IQEC-CLEO.2011.6194137; http://www.opticsinfobase.org/abstract.cfm?URI=CLEOPR-2011-C1094.

7. S. Y. Kalmykov, X. Davoine, and B. A. Shadwick, Sub-millimeter-scale, 100-MeV-class quasimonoenergetic laser plasma accelerator based on all-optical control of dark current in the blowout regime, in The 15th Advanced Accelerator Concepts Workshop, R. B. Zgadzaj, E. W. Gaul, and M. C. Downer, Editors, AIP Proc. 1507, 289-294 (2012); http://dx.doi.org/10.1063/1.4773709.

8. B. M. Cowan, S. Y. Kalmykov, B. A. Shadwick, K. Bunkers, D. L. Bruhwiler, and D. P. Umstadter, Improved particle statistics for laser-plasma self-injection simulations, in The 15th Advanced Accelerator Concepts Workshop, R. B. Zgadzaj and E. W. Gaul, Editors, AIP Conf. Proc. 1507, 375-380 (2012); http://dx.doi.org/10.1063/1.4773725.

9. Frank M. Lee and B. A. Shadwick, Modeling asymmetric beams using higher-order phase-space moments, in The 15th Advanced Accelerator Concepts Workshop, R. B. Zgadzaj and E. W. Gaul, Editors, AIP Conf. Proc. 1507, 393-398 (2012); http://dx.doi.org/10.1063/1.4773728. 
10. S. Y. Kalmykov, Dark-current-free laser-plasma acceleration in blowout regime using nonlinear plasma lens, in The $15^{\text {th }}$ Advanced Accelerator Concepts Workshop, R. B. Zgadzaj, E. W. Gaul, and M. C. Downer, Editors, AIP Conf. Proc. 1507, 921-926 (2013); http://dx.doi.org/10.1063/1.4788989.

11. J. Paxon Reyes and B. A. Shadwick, An unconditionally-stable numerical method for laser-plasma interactions, in The $15^{\text {th }}$ Advanced Accelerator Concepts Workshop, R. B. Zgadzaj, E. W. Gaul, and M. C. Downer, Editors, AIP Conf. Proc. 1507, 939-944 (2013);

http://dx.doi.org/10.1063/1.4788992.

\section{CONFERENCE PRESENTATIONS.}

\section{Invited talks:}

1. B. A. Shadwick, Nonlinear depletion and dephasing in laser wakefield accelerators, APS $50^{\text {th }}$ Annual Meeting of the Division of Plasma Physics, Dallas, Texas; November 17-21 (2008); invited DI2.00003; abstract published in Bull. Am. Phys. Soc. 53(14) (2008); report published in Phys. Plasmas 16, 056704 (2009). (http://meetings.aps.org/link/BAPS.2008.DPP.DI2.3)

2. S. Y. Kalmykov, Electron self-injection into an evolving plasma bubble: toward a dark current free $\mathrm{GeV}$-scale laser plasma accelerator, APS $52^{\text {nd }}$ Annual Meeting of the Division of Plasma Physics, Chicago, Illinois; November 8-12 (2010); invited KI3.00003; abstract published in Bull. Am. Phys. Soc. 55(15), 190 (2010); report published in Phys. Plasmas 18(5), 056704 (2011). (http://meetings.aps.org/link/BAPS.2010.DPP.KI3.3)

3. B. A. Shadwick, Variational Formulation of Macro-Particle Algorithms for Kinetic Plasma Simulations, 2013 International Sherwood Fusion Theory Conference, Santa Fe, April 15-17, 2013.

4. B. A. Shadwick, Variational Formulation of Macro-Particle Algorithms for Kinetic Plasma Simulations, APS $55^{\text {th }}$ Annual Meeting of the Division of Plasma Physics, Denver, Colorado; November 11-15 (2013).

\section{Contributed poster and oral presentations:}

1. B. A. Shadwick and C. B. Schroeder, Physical fidelity in particle-in-cell modeling of small Debyelength plasmas, The $13^{\text {th }}$ Advanced Accelerator Concepts Workshop, Santa Cruz, CA, July 27Aug. 2 (2008), oral; report published in AIP Conf. Proc. 1086, 321-327 (2009).

2. Carl Schroeder, Eric Esarey, Wim Leemans, and Bradley Shadwick, Nonlinear transport velocity and evolution of intense short-pulse lasers in underdense plasma, APS $50^{\text {th }}$ Annual Meeting of the Division of Plasma Physics, Dallas, Texas; November 17-21 (2008); poster PP6.00052; abstract published in Bull. Am. Phys. Soc. 53(14) (2008);

http://meetings.aps.org/link/BAPS.2008.DPP.PP6.52

3. E. G. Evstatiev and B. A. Shadwick, Electron heating by plasma waves, APS $50^{\text {th }}$ Annual Meeting of the Division of Plasma Physics, Dallas, Texas; November 17-21 (2008); poster PP6.00059; abstract published in Bull. Am. Phys. Soc. 53(14) (2008);

(http://meetings.aps.org/link/BAPS.2008.DPP.PP6.59) 
4. B. A. Shadwick, C. B. Schroeder, and E. Esarey, Nonlinear laser energy depletion in laser-plasma accelerators, APS $51^{\text {st }}$ Annual Meeting of the Division of Plasma Physics, Atlanta, Georgia, November 2-6 (2009); poster JP8.00128; abstract published in Bull. Am. Phys. Soc. 54(15) (2009) (http://meetings.aps.org/link/BAPS.2009.DPP.JP8.128)

5. E. Esarey, C. B. Schroeder, C. G. R. Geddes, E. Cormier-Michel, W. P. Leemans, D. Bruhwiler, B. Cowan, and B. A. Shadwick, Physics of a $10 \mathrm{GeV}$ laser-plasma accelerator, APS $51^{\text {st }}$ Annual Meeting of the Division of Plasma Physics, Atlanta, Georgia, November 2-6 (2009); poster JP8.00129; abstract published in Bull. Am. Phys. Soc. 54(15) (2009)

(http://meetings.aps.org/link/BAPS.2009.DPP.JP8.129)

6. S. Y. Kalmykov, A. Beck, E. Lefebvre, S. A. Yi, V. Khudik, G. Shvets, M. C. Downer, D. Bruhwiler, and B. A. Shadwick, Electron self-injection into an evolving plasma bubble: The way to a dark current free GeV-scale laser plasma accelerator, The $14^{\text {th }}$ Advanced Accelerator Concepts Workshop, Annapolis, Maryland, June 13-19 (2010), oral; report published in AIP Conf. Proc. 1299, 174-179 (2010).

7. B. A. Shadwick, F. Lee, M. M. Tassi, and G. M. Tarkenton, Self-Consistent Hamiltonian Model of Beam Transport in a Laser-Driven Plasma Accelerator, The $14^{\text {th }}$ Advanced Accelerator Concepts Workshop, Annapolis, Maryland, June 13-19 (2010) oral; report published in AIP Conf. Proc. 1299, 221-226 (2010).

8. J. Paxon Reyes and B. A. Shadwick, Numerical Methods for the Wave Equation, The $14^{\text {th }}$ Advanced Accelerator Concepts Workshop, Annapolis, Maryland, June 13-19 (2010), oral; report published in AIP Conf. Proc. 1299, 256-261 (2010).

9. S. Y. Kalmykov, B. A. Shadwick, and M. C. Downer, Train of relativistically intense few-cycle radiation pulses: Novel optical source based on non-resonant amplitude self-modulation and electromagnetic cascading in plasmas, The $14^{\text {th }}$ Advanced Accelerator Concepts Workshop, Annapolis, Maryland, June 13-19 (2010); report published in AIP Conf. Proc. 1299, 752-757 (2010).

10. J. Paxon Reyes and B. A. Shadwick, Numerical methods for the 1D quasistatic wave equation, APS $52^{r d}$ Annual Meeting of the Division of Plasma Physics, Chicago, Illinois, November 8-12 (2010); poster GP9.00008; abstract published in Bull. Am. Phys. Soc. 55(15), 123 (2010) (http://meetings.aps.org/link/BAPS.2010.DPP.GP9.8)

11. B. A. Shadwick, C. B. Schroeder, J. Paxton Reyes, Carlo Benedetti, and E. Esarey, The physics of reduced models of intense laser-plasma interactions, APS $52^{\text {rd }}$ Annual Meeting of the Division of Plasma Physics, Chicago, Illinois, November 8-12 (2010); poster GP9.00009; abstract published in Bull. Am. Phys. Soc. 55(15), 123 (2010) (http://meetings.aps.org/link/BAPS.2010.DPP.GP9.9)

12. Carl Schroeder, Carlo Benedetti, Eric Esarey, Wim Leemans, and Bradley Shadwick, Nonlinear phase velocity of relativistic plasma waves driven by intense lasers, APS $52^{\text {rd }}$ Annual Meeting of the Division of Plasma Physics, Chicago, Illinois, November 8-12 (2010); poster GP9.00022; abstract published in Bull. Am. Phys. Soc. 55(15), 126 (2010)

(http://meetings.aps.org/link/BAPS.2010.DPP.GP9.22)

13. Evstati Evstatiev and Bradley Shadwick, Particle algorithms as reductions of phase space, APS $52^{r d}$ Annual Meeting of the Division of Plasma Physics, Chicago, Illinois, November 8-12 (2010); poster TP9.00036; abstract published in Bull. Am. Phys. Soc. 55(15), 308 (2010)

(http://meetings.aps.org/link/BAPS.2010.DPP.TP9.36) 
14. S. Y. Kalmykov, K. Bunkers, B. A. Shadwick, A. Beck, E. Lefebvre, B. M. Cowan, and D. L. Bruhwiler, Modeling multi-GeV, single-stage laser-plasma electron accelerators driven by self-guided petawatt laser pulses, Laser and Plasmas Accelerator Workshop 2011 (LPAW 2011), Wuzhen, China, June 20-24 (2011), poster; report published in J. Plasma Phys. 78(4), 469 - 482 (2012).

15. Sudeep Banerjee, Serguei Kalmykov, Nathan Powers, Vidya Ramanathan, Nate Smith, Kevin Brown, S. Chen, Anand Moorti, Isaac Ghebregziabher, and Donald Umstadter, Background-Free, Quasi-Monoenergetic Electron Beams from a Self-Injected Laser Wakefield Accelerator, International Quantum Electronics Conference (IQEC) and Conference on Lasers and Electro-Optics (CLEO) Pacific Rim (Incorporating the Australasian Conference on Optics, Lasers and Spectroscopy and the Australian Conference on Optical Fibre Technology), High Power Laser Physics (4640), Symposium 4, Sydney Convention and Exhibition Centre, Australia, August 28-September 1 (2011); invited 4640-IT-1 (www.iqec-cleopr2011.com); report published in Proceedings of the International Quantum Electronics Conference and Conference on Lasers and Electro-Optics Pacific Rim 2011 (Optical Society of America, 2011), paper C1094

(http://www.opticsinfobase.org/abstract.cfm?URI=CLEOPR-2011-C1094).

16. Benjamin Cowan, Estelle Cormier-Michel, David Bruhwiler, Serguei Kalmykov, Bradley Shadwick, Kyle Bunkers, and Donald Umstadter, Simulation methods for laser-plasma based $x$-ray sources, APS $53^{\text {rd }}$ Annual Meeting of the Division of Plasma Physics, Salt Lake City, Utah, November 14-18 (2011); oral TO7.00008; abstract published in Bull. Am. Phys. Soc. 56(16), 289 (2011) (http://meetings.aps.org/link/BAPS.2011.DPP.TO7.8)

17. S. Y. Kalmykov, B. A. Shadwick, A. Beck, and E. Lefebvre, Controlling nonlinear optical evolution of the laser pulse for dark-current-free electron acceleration in the blowout regime, APS $53^{r d}$ Annual Meeting of the Division of Plasma Physics, Salt Lake City, Utah, November 14-18 (2011); poster BP9.00120; abstract published in Bull. Am. Phys. Soc. 56(16), 51 (2011)

(http://meetings.aps.org/link/BAPS.2011.DPP.BP9.120)

18. K. Bunkers, S. Y. Kalmykov, B. A. Shadwick, D. P. Umstadter, A. Beck, E. Lefebvre, B. M. Cowan, and D. L. Bruhwiler, Modeling GeV-class single-stage laser-plasma electron acceleration in the blowout regime, APS $53^{\text {rd }}$ Annual Meeting of the Division of Plasma Physics, Salt Lake City, Utah, November 14-18 (2011); poster BP9.00121; abstract published in Bull. Am. Phys. Soc. 56(16), 51 (2011) (http://meetings.aps.org/link/BAPS.2011.DPP.BP9.121)

19. J. Paxon Reyes and B. A. Shadwick, Numerical methods for laser-plasma interactions, APS $53^{\text {rd }}$ Annual Meeting of the Division of Plasma Physics, Salt Lake City, Utah, November 14-18 (2011); poster BP9.00122; abstract published in Bull. Am. Phys. Soc. 56(16), 51 (2011) (http://meetings.aps.org/link/BAPS.2011.DPP.BP9.122)

20. B. A. Shadwick, Frank M. Lee, and Luke Faeh, A reduction of the Vlasov-Maxwell system using phase-space blobs, APS $53^{\text {rd }}$ Annual Meeting of the Division of Plasma Physics, Salt Lake City, Utah, November 14-18 (2011); poster BP9.00122; abstract published in Bull. Am. Phys. Soc. 56(16), 205 (2011) (http://meetings.aps.org/link/BAPS.2011.DPP.NP9.28)

21. Sudeep Banerjee, Generation, and applications of stable, 100-500-MeV, dark-current-free beams, from a laser-wakefield accelerator, APS $53^{\text {rd }}$ Annual Meeting of the Division of Plasma Physics, Salt Lake City, Utah, November 14-18 (2011); invited UI2.00006; abstract published in Bull. Am. Phys. Soc. 56(12), 323 (2011) (http://meetings.aps.org/link/BAPS.2011.DPP.UI2.6) 
22. B. M. Cowan, S. Y. Kalmykov, B. A. Shadwick, K. Bunkers, D. L. Bruhwiler, and D. P. Umstadter, Improved particle statistics for laser-plasma self-injection simulations, The $15^{\text {th }}$ Advanced Accelerator Concepts Workshop, Austin, Texas, June 11-15 (2012), oral; report published in AIP Conf. Proc. 1507, 375-380 (2012).

23. Frank M. Lee and B. A. Shadwick, Modeling asymmetric beams using higher-order phase-space moments, The $15^{\text {th }}$ Advanced Accelerator Concepts Workshop, Austin, Texas, June 11-15 (2012), oral; report published in AIP Conf. Proc. 1507, 393-398 (2012).

24. S. Y. Kalmykov, B. A. Shadwick, X. Davoine, A. Beck, and E. Lefebvre, Managing relativistic optical phenomena: An all-optical route to quasi-monoenergetic $\mathrm{GeV}$ electron beams generated with sub-100 TW laser pulses in mm-scale, high-density plasmas, The $15^{\text {th }}$ Advanced Accelerator Concepts Workshop, Austin, Texas, June 11-15 (2012), oral; report published in AIP Conf. Proc. 1507, 289-294 (2012).

25. S. Y. Kalmykov, Dark-current-free acceleration in the blowout regime using nonlinear plasma lens, The 15 ${ }^{\text {th }}$ Advanced Accelerator Concepts Workshop, Austin, Texas, June 11-15 (2012), oral; report published in AIP Conf. Proc. 1507, 921-926 (2013).

26. J. Paxon Reyes and B. A. Shadwick, An unconditionally-stable numerical method for laser-plasma interactions, The $15^{\text {th }}$ Advanced Accelerator Concepts Workshop, Austin, Texas, June 11-15 (2012), oral; report published in AIP Conf. Proc. 1507, 939-944 (2013).

27. Benjamin Cowan, David Leslie Bruhwiler, John R. Cary, Kyle Bunkers, Serguei Kalmykov, Brad Shadwick, and Donald Umstadter, Improved particle statistics for laser-plasma self-injection simulations, 11th International Computational Accelerator Physics Conference (ICAP), RostockWarnemünde, Germany, August 19-24 (2012); poster TUSBC3; http://accelconf.web.cern.ch/AccelConf/ICAP2012/talks/tusbc3 talk.pdf

28. Michaël Carrié and B. A. Shadwick, An Implicit Solver for the Vlasov-Poison Equation, APS $54^{\text {th }}$ Annual Meeting of the Division of Plasma Physics, Providence, Rhode Island, October 29November 2 (2012); poster UP8.00022; abstract published in Bull. Am. Phys. Soc. 57(12) (2012) (http://meetings.aps.org/link/BAPS.2012.DPP.UP8.22).

29. Jonathan Reyes and B. A. Shadwick, An unconditionally-stable numerical method for laser-plasma interactions, APS $54^{\text {th }}$ Annual Meeting of the Division of Plasma Physics, Providence, Rhode Island, October 29-November 2 (2012); poster PP8.00114; abstract published in Bull. Am. Phys. Soc. 57(12) (2012) (http://meetings.aps.org/link/BAPS.2012.DPP.PP8.114).

30. S. Y. Kalmykov, B. A. Shadwick, and X. Davoine, Ultracompact quasi-monoenergetic GeV-scale laser plasma accelerator based on all-optical control of dark current in longitudinally tapered plasmas, APS $54^{\text {th }}$ Annual Meeting of the Division of Plasma Physics, Providence, Rhode Island, October 29-November 2 (2012); poster PP8.00113; abstract published in Bull. Am. Phys. Soc. 57(12) (2012) (http://meetings.aps.org/link/BAPS.2012.DPP.PP8.113).

31. B. M. Cowan, S. Y. Kalmykov, K. Bunkers, J. Cary, B. A. Shadwick, and D. P. Umstadter, Improved Particle Statistics for Laser-Plasma Self-Injection Simulations, APS $54^{\text {th }}$ Annual Meeting of the Division of Plasma Physics, Providence, Rhode Island, October 29-November 2 (2012); poster PP8.00115; abstract published in Bull. Am. Phys. Soc. 57(12) (2012) (http://meetings.aps.org/link/BAPS.2012.DPP.PP8.115). 